REVISTA DE DERECHO UNED, núm. 2, 2007

\title{
LA DENEGACIÓN DEL SUPLICATORIO Y SU INCIDENCIA EN EL DERECHO A LA TUTELA JUDICIAL EFECTIVA
}

\author{
M. ${ }^{a}$ ISABEL MARTÍN DE Llano ${ }^{1}$
}

Resumen: Este trabajo tiene por objeto ofrecer un breve análisis de la prerrogativa de la inmunidad parlamentaria en relación con el derecho a la tutela judicial efectiva. Conforme a lo establecido en una Ley preconstitucional de 1912, si la Cámara Legislativa deniega un suplicatorio, la causa penal se archiva de forma definitiva sin poder reabrirla en un futuro cuando el parlamentario implicado abandone su cargo. Nosotros realizamos un análisis del derecho a la tutela judicial efectiva en sede constitucional, con el fin de comprobar si dicha Ley de 1912 es contraria o no al mencionado derecho reconocido en el artículo 24 de la Constitución Española.

Palabras clave: Suplicatorio/ Rogatory letter. Inmunidad parlamentaria/ Parliamentary immunity. Tutela judicial efectiva/ Right to the effective judicial protection.

Abstact: The aim of this work is to present a concise analysis of the parliamentary immunity prerogative in relation to the right to the effective judicial protection. According to that established in a preconstitutional Law of 1912, if the Legislative Chamber denies a rogatory letter, the criminal case is definitively rejected and it can not be reopen in the future, when the parliamentarian involved in the case leaves his or her position. We have made an analysis of the right to the effective judicial protection in the constitutional seat in order to verify if the aforementioned Law of 1912 is or is not contrary

1 Doctora en Derecho por la UNED. Profesora Asociada de Derecho Constitucional en la Facultad de Derecho de la UNED. 
to that right, which is recognized in the article 24 of the Spanish Constitution.

Sumario: I. LA TUTELA JUDICIAL EFECTIVA COMO DERECHO FUNDAMENTAL.-II. LA INMUNIDAD PARLAMENTARIA Y SU INCIDENCIA EN LA TUTELA JUDICIAL EFECTIVA.-II. 1. El conflicto entre el suplicatorio y el contenido del derecho a la tutela judicial efectiva.-II. 1. A. El derecho de libre acceso a la jurisdicción.-II. 1. B. El derecho de libre acceso al proceso.-II. 1. C. El derecho a no sufrir indefensión.-II. 1. D. El derecho a obtener una resolución fundada en Derecho.-III. CONCLUSIONES.

\section{LA TUTELA JUDICIAL EFECTIVA COMO DERECHO FUNDAMENTAL}

El fundamento básico del derecho a la tutela judicial efectiva se encuentra en el hecho de que a las personas se les ha prohibido satisfacer por sus propios medios el conjunto de derechos e intereses que constituyen su patrimonio jurídico. El ordenamiento positivo prevé la solución de conflictos siguiendo la pauta de convenciones sociales ordenadas a la idea de justicia. Sobre la base de esta prohibición de las iniciativas individuales, será necesaria una compensación que permita solicitar esa defensa al Estado poniendo en marcha el mecanismo de la justicia, gracias a lo que se denomina derecho a la jurisdicción. De esta forma se impone un orden jurídico en que prevalece el criterio del sujeto imparcial, sustituyendo la acción directa frente al adversario por la acción dirigida hacia el Estado con el fin de que los órganos especialmente creados para ello acojan las pretensiones deducidas por un sujeto frente a otro.

Es necesario que el Estado cree los instrumentos adecuados para que los ciudadanos puedan ver satisfechas sus pretensiones, porque de lo contrario se asistirá a un resurgimiento de la autotutela en la búsqueda extrainstitucional del deseo de justicia que puede llevar a una crisis social, y por tanto jurídica. Por eso es de destacar la importancia, para la estabilidad del sistema político, de una verdadera tutela jurisdiccional, que se ha de reconocer como un auténtico derecho a todo aquel que, sufriendo una violación, pueda acudir a un órgano estatal que le atienda y que haga efectivos sus derechos en el caso de que lo juzgue procedente. 
Como afirma FIGUERUELO BURRIEZA es una constante el considerar que «el derecho a la jurisdicción no constituye una conquista del Estado de Derecho, ya que la organización del poder público de modo que la Justicia quede garantizada le viene impuesta a todo Estado por principios superiores que el Derecho positivo no puede desconocer. El derecho a la jurisdicción existe con independencia de su reconocimiento en las Declaraciones de Derechos Humanos, en los Pactos Internacionales, en las Constituciones o Leyes de cada Estado. Como los demás derechos humanos, es un derecho que corresponde a todos los hombres por el mero hecho de serlo. Los ordenamientos jurídicos se limitan a positivizarlo, al igual que hacen otros principios del Derecho Natural ${ }^{2}$. Sin embargo, cuando la doctrina científica busca una definición del concepto de "derecho fundamental», no rehuye la referencia clara al texto Constitucional, algo que se comprueba cuando se afirma que los derechos fundamentales son «los derechos naturales constitucionalizados sobre la base del principio de soberanía popular», y que «tienen que incorporarse a una Constitución que se afirme expresamente como norma jurídica y que prevea mecanismos para garantizar su supremacía» ${ }^{3}$.

Al tiempo que para su realización efectiva es necesaria la intervención de los operadores jurídicos. Es la participación activa del Estado, que busca garantizar el ejercicio real y efectivo de los derechos fundamentales, la que determina el carácter democrático de un Estado. Sin olvidar que la democracia no depende del número de derechos reconocidos por el Estado, sino de la garantía de los mismos. El calificativo "fundamentales» expresa la esencial dimensión de lo humano y su prioridad axiológica, como su función cimentadora, fundamentadora del poder político. "A nadie puede ofrecer duda la importancia del efectivo y cotidiano ejercicio de los derechos fundamentales y las libertades públicas y de su enraizamiento en los hábitos de comportamiento que forman la trama real de la vida cotidiana. Una incondicionada lealtad en el ejercicio y en el respeto de tales derechos y libertades ha de ser el foco iluminador de los diálogos básicos de la democracia» ${ }^{4}$.

2 FIGUERUELO BURRIEZA, A.: El derecho a la tutela judicial efectiva, Madrid, Tecnos, 1990 , págs. 50 y 51.

3 ABA CATOIRA, A.: La limitación de los derechos en la jurisprudencia del Tribunal Constitucional español, Valencia, Tirant lo Blanch, 1999, pág. 34.

4 LAVILLA ALSINA, L.: "Derechos fundamentales, Estado y Sociedad", en La garantía Constitucional de los derechos fundamentales. Alemania, España, Francia e Italia (dir. Antonio López Pina), Servicio de Publicaciones Facultad de Derecho-Universidad Complutense Madrid, 1991, pág. 30. 
En la búsqueda de la efectividad y realización de los derechos fundamentales, la Constitución no es plena ni concreta, sino que reconoce y garantiza de forma muy general un conjunto de derechos y libertades, con el fin de que sea el legislador el que opere sobre el contenido material del derecho en cuestión. Como afirma el Tribunal Constitucional, con la constitucionalización de los derechos se consigue «no la mera enunciación formal de un principio hasta ahora no explicitado sino la plena positivización de un derecho a partir del cual cualquier ciudadano podrá recabar su tutela ante los Tribunales ordinarios (art. 53.2 CE), y su elevación al rango de derecho fundamental de conformidad con el cual deben ser interpretadas todas las normas que componen nuestro ordenamiento ${ }^{5}$.

De esta forma, en su vertiente material, los derechos fundamentales son aquéllos considerados como tales en la conciencia y en la cultura jurídicas en las que se inserta el Estado constitucional español. Mientras que en su vertiente formal, el contenido esencial de los derechos fundamentales se integraría por un elemento genérico común a todo derecho, la garantía judicial, y un elemento específico de todo derecho fundamental: la vinculación del Legislador.

Admitida la intervención legislativa en el ámbito constitucionalmente protegido de los derechos fundamentales, deberá el legislador tener en cuenta la llamada "cultura de los derechos fundamentales». Es decir, la garantía de los derechos fundamentales es obra de una serie de factores estatales, públicos y privados combinados: junto a la garantía de los derechos fundamentales por los poderes públicos, juegan la doctrina y sus construcciones dogmáticas, la opinión pública, partidos y grupos, el compromiso de los ciudadanos, sus orientaciones y valores respecto a los derechos fundamentales. De esta forma, la efectividad ${ }^{6}$ de los derechos fundamentales no es la consecuencia automática de un orden abstracto de eficacia o de la eficacia vinculante de un texto, sino que es el resultado complejo y pleno de riesgos, de procesos pluriarticulados de interpretación de numerosos participantes: de los destinatarios y titulares de los derechos fundamentales, en fin, de la entera res pública como contexto cultural de los derechos fundamentales ${ }^{7}$.

5 STC 56/1982, de 26 de julio, Fj. 2..

6 Hablamos de efectividad en el sentido de derecho real y verdadero, por contraposición a lo quimérico o nominal.

7 HÄBERLE, P; "Jurisprudencia Constitucional», en La garantia Constitucional de los derechos fundamentales. Alemania, España, Francia e Italia (dir. Antonio López Pina), Servicio de Publicaciones Facultad de Derecho-Universidad Complutense Madrid, 1991, pág. 269. 
En este sentido «habrá que determinar cómo concurren en el ordenamiento las normas que los reconocen y garantizan y aquellas otras que, revistiendo rango infraconstitucional, vienen a completarlos desarrollándolos, regulándolos, limitándolos y, en definitiva, configurándolos» ${ }^{8}$.

\section{LA INMUNIDAD PARLAMENTARIA Y SU INCIDENCIA EN LA TUTELA JUDICIAL EFECTIVA.}

El artículo 24 de la Constitución Española de 1978 establece que:

Art.24.1: «Todas las personas tienen derecho a obtener la tutela efectiva de los jueces y tribunales en el ejercicio de sus derechos e intereses legítimos, sin que, en ningún caso pueda producirse indefensión.

2. Asimismo, todos tienen derecho al Juez ordinario predeterminado por la ley, a la defensa y a la asistencia de letrado, a ser informados de la acusación formulada contra ellos, a un proceso público sin dilaciones indebidas y con todas las garantías, a utilizar los medios de prueba pertinentes para su defensa, a no declarar contra sí mismos, a no confesarse culpables y a la presunción de inocencia.

La ley regulará los casos en que, por razón de parentesco o de secreto profesional, no se estará obligado a declarar sobre hechos presuntamente delictivos»

La impronta de la Constitución afecta a todo el ordenamiento jurídico en ella fundamentado, incluido el Derecho Procesal, entendido como aquella rama de la disciplina que transforma en efectivas las promesas de certidumbre y coerción propias de las normas jurídicas.

Con carácter general la satisfacción de las distintas pretensiones que en el marco de la Justicia pueda tener una persona, corresponderá a los Jueces y Tribunales, que son los que han de otorgar la tutela judicial efectiva y los únicos, en consecuencia, a los que cabe imputar su violación (STC 26/1983, de 13 de abril). Algo, sin embargo, que sin dejar de ser cierto, debe ser matizado, pues existen órganos de carácter no jurisdiccional, como las Cámaras parlamentarias, que con sus decisiones pueden afectar al derecho a la tutela judicial efec-

8 ABA CATOIRA, A.: La limitación de los derechos..., op. cit. pág. 50. 
tiva de terceros, al no permitir o dificultar al interesado el acceso a los Tribunales de Justicia ${ }^{9}$.

Esta incidencia se produce, cuando en el ejercicio de las prerrogativas parlamentarias, las Cámaras resuelven acerca de la solicitud para procesar a alguno de sus miembros. Ha de tenerse en cuenta que la Constitución mediante el artículo 71.2, ha querido que, en relación a los delitos presuntamente cometidos por los Diputados o Senadores, sea la correspondiente Cámara la que decida acerca de la posibilidad de perseguir o no dichos delitos ante la jurisdicción penal. Es decir, en tales supuestos, son los órganos parlamentarios los que adoptan decisiones que afectan a la tutela judicial de los ciudadanos afectados por las conductas supuestamente delictivas.

Es claro que los Jueces y Tribunales son los únicos que administran Justicia, pero pueden verse limitados en su conocimiento por la inmunidad parlamentaria, dado que la autorización para proceder contra un parlamentario, se concede o no, a voluntad exclusiva del órgano legislador. El problema radica, no en la paralización temporal de la Justicia mientras se resuelve el suplicatorio, sino en que si éste se rechaza, la causa será cerrada definitivamente, impidiendo al tercero implicado obtener de los Tribunales de Justicia una resolución sobre el fondo para ver satisfecha, en su caso, su pretensión.

Como ha indicado el Tribunal Constitucional y la mayoría de la doctrina, la inmunidad parlamentaria tiene por fin evitar que por persecuciones políticas se altere la composición de las Cámaras y su adecuado funcionamiento; ahora bien, si el que era parlamentario deja de serlo, no debe impedirse que los órganos jurisdiccionales conozcan de las causas penales en las que estaban implicados cuando ostentaban el cargo representativo, pues es claro que afecta a la tutela judicial de terceras personas y que no se altera en absoluto la independencia ni el funcionamiento de la Cámara a la que pertenecía el ex-parlamentario.

Lo que nos planteamos es hasta qué punto la inmunidad y las normas procesales que le son de aplicación son compatibles con el derecho a la tutela judicial efectiva. No se trata de un conflicto entre dos preceptos constitucionales donde deba prevalecer el de mayor fuerza. Tal planteamiento no sería correcto ni adecuado, pues como ha afirmado el Tribunal Constitucional, la Constitución "no es la suma y el agregado de una multiplicidad de mandatos inconexos,

${ }^{9} \operatorname{SSTC} 90 / 1985, \mathrm{Fj} .4 .^{\circ}$ y $243 / 1988$. 
sino el orden jurídico fundamental de la comunidad política, regido y orientado a su vez por la proclamación del artículo 1, en su apartado primero, a partir del cual debe resultar un sistema coherente en el que todos sus contenidos encuentran el espacio y la eficacia que el Constituyente quiso otorgarles ${ }^{10}$.

Se trata, por tanto, de preservar un derecho fundamental, el derecho a la tutela judicial efectiva de los Jueces, en la medida que éste puede resultar obstaculizado por la inmunidad parlamentaria.

\section{II.1. EL CONFLICTO ENTRE EL SUPLICATORIO Y EL CONTENIDO DEL DERECHO A LA TUTELA JUDICIAL EFECTIVA.}

La pluralidad de posiciones doctrinales ${ }^{11}$ y la prolija Jurisprudencia sobre el «derecho a la tutela judicial efectiva de los jueces y tri-

10 STC 206/1992, de 27 de noviembre, Fj. 1..

11 GONZÁLEZ PÉREZ entiende que todo el artículo 24 de la CE no tiene más contenido que la tutela, siendo los distintos derechos que en él se enumeran meras concreciones de aquélla (El derecho a la tutela jurisdiccional, Madrid, Civitas, 2001, pág 58). PIÑEL LÓPEZ mezcla el contenido de los números $10^{\circ}$ y $2 .^{\circ}$ del artículo 24 de la $\mathrm{CE}$, y considera que la tutela judicial efectiva es «... el derecho que tienen todas las personas a obtener la tutela efectiva de sus derechos e intereses legítimos ante el Juez ordinario predeterminado por la Ley y a través de un proceso con todas las garantías, sin dilaciones indebidas, y en el que no se produzca indefensión, al poder utilizar los medios de prueba pertinentes para su defensa» («El derecho a la tutela jurídica por los Tribunales de justicia», en El Poder Judicial, (Dirección General de lo Contencioso del Estado), Madrid, Instituto de Estudios Fiscales, 1983, pág. 293). LORENTE considera que frente al derecho a la acción, el art. 24 CE consagra el derecho a la instancia como derecho a un determinado contenido de la decisión jurisdiccional ( El derecho a la tutela judicial efectiva en la doctrina del Tribunal Constitucional», en Poder Judicial, n. ${ }^{\circ}$ 3, 1982, págs. 107-112).

GONZALEZ MONTES entiende que el derecho a la tutela jurisdiccional vendría a coincidir con el derecho a la actividad procesal, y en su caso, a una resolución de fondo (de darse los presupuestos procesales), y cree además que la indefensión es algo diferente al derecho a la tutela jurisdiccional (Homenaje a José Antonio García Trevijano Fos, Madrid, Instituto de Estudios de Administración Local, 1982, págs. 1493 y 1490). REYES MONTERREAL mantiene que el derecho a la tutela judicial efectiva es el derecho a la jurisdicción que se haría efectivo simplemente con abrir el proceso y tener a la persona como parte («Tutela judicial efectiva, presupuestos procesales y requisitos formales», en Actualidad Administrativa, n. ${ }^{\circ} 36,1988$, pág.2095 ). GOMEZ-FERRER MORANT estima que el derecho a la tutela judicial efectiva comprende el derecho de acceso a la justicia, el de obtener una resolución fundada en Derecho y el de que se ejecuten las resoluciones judiciales ( La tutela judicial efectiva como derecho fundamental», en De la jurisprudencia del Tribunal Constitucional (Seminario de profesores de la Facultad de Derecho —dirigido por L. Martín-Retortillo Baquer), Zaragoza, 1985, pág. 17). GARCIA MORILLO define la tutela judicial como el derecho de 
bunales», ponen de manifiesto la complejidad del contenido del artículo 24 de la Constitución.

Desde un principio el Tribunal Constitucional ha entendido que el artículo 24 de la Constitución contiene distintas cláusulas perfectamente diferenciadas, de forma que el derecho a la tutela judicial efectiva, enunciado en el artículo 24.1, engloba distintos derechos:

\section{II.1.A. El derecho de libre acceso a la jurisdicción}

Este derecho es considerado por el Tribunal Constitucional como el primer escalón en el ejercicio del derecho a la prestación jurisdiccional (STC 6/1989, de 19 de enero, Fj. 2). El artículo 24.1 CE garantiza el acceso a la jurisdicción como elemento esencial del contenido de la tutela judicial, consistente en provocar la actividad jurisdiccional que desemboque en la decisión de un Juez sobre las pretensiones deducidas (STC 124/2002, de 20 de mayo, Fj. 3) ${ }^{12}$. Cuando el Legislador imponga requisitos que dificulten o entorpezcan la posibilidad de actuar por vía jurisdiccional, deberá obedecer a la finalidad de proteger otros bienes o intereses constitucionalmente protegidos y deberá guardar proporcionalidad con la carga de diligencia exigible a los justiciables (SSTC 60/1989, de 16 de marzo, Fj. 4; 158/1987, de 20 de octubre, Fj. 4).

Así, los órganos judiciales están constitucionalmente obligados a aplicar las normas que contienen requisitos procesales, teniendo presente el fin perseguido por el legislador al establecerlos, evitando cualquier exceso formalista que los convierta en meros obstáculos procesales impeditivos de la tutela judicial efectiva que garantiza el art. 24.1 CE (STC 12/2003, de 28 de enero, Fj. 4) ${ }^{13}$ y, evitando, aquellas interpretaciones de las normas que sean manifiestamente erróneas, irrazonables o basadas en criterios que por cualquier razón revelen una clara desproporción entre los fines que la causa preserva

todas las personas a tener acceso al sistema judicial y a ejercer, en el seno del proceso, todas sus facultades para que los órganos jurisdiccionales estudien su pretensión y emitan una resolución motivada y conforme a derecho (Derecho Constitucional, Vol. I, Valencia, 1991, págs. 277-278).

12 En el mismo sentido SSTC 12/2003, de 28 de enero, Fj. 4; 71/2001, de 26 de marzo, Fj. 3; 189/1999, de 25 de octubre, Fj. 2; 132/1997, Fj. 2;; 220/1993, de 30 de junio, Fj. 3 . tubre.

${ }_{13}$ En el mismo sentido SSTC 108/2000, de 5 de mayo, Fj. 3; 157/1989, de 5 de oc- 
y los intereses que se sacrifican (SSTC 124/2002, de 20 de mayo, Fj. 3) ${ }^{14}$.

En nuestro caso, cuando las Cámaras legislativas deniegan el suplicatorio y, como consecuencia de ello, por aplicación del artículo 7 de la Ley sobre Jurisdicción y procedimientos especiales en las causas contra Senadores y Diputados de 1912, los órganos judiciales decretan el sobreseimiento libre, se está impidiendo totalmente la posibilidad de que, una vez que el parlamentario implicado en un proceso penal pierda su condición de representante político, se acuda a la vía jurisdiccional para que el tercero afectado vea satisfechas sus pretensiones. Impedimento que en esta situación no obedece a la finalidad de proteger otros bienes o intereses constitucionalmente protegidos y que no guarda proporción alguna con las consecuencias que produce.

Si tenemos en cuenta la jurisprudencia constitucional arriba reseñada, vemos cómo la aplicación del artículo 7 de la Ley de 9 de febrero de 1912, es totalmente contraria al derecho a la tutela judicial efectiva concretada en el derecho de acceso a la jurisdicción.

En este sentido el Tribunal Constitucional ha afirmado que la Constitución con su artículo 71.2 ha querido que sea la Cámara la que decida sobre la posibilidad de perseguir o no por vía penal las actuaciones de sus miembros, adoptando decisiones acerca del acceso a la tutela judicial por parte de los ciudadanos afectados por las conductas presuntamente delictivas de los parlamentarios ${ }^{15}$.

Por ello, el Tribunal Constitucional a partir de la sentencia $90 / 1985^{16}$, exige que el acuerdo de la Cámara por el que se deniega un suplicatorio deba estar motivado y sea conforme a los fines que persigue la inmunidad parlamentaria, pues de lo contrario se vulnerará la tutela judicial efectiva concretada en el derecho de acceso a la jurisdicción.

\section{II.1.B. El derecho de libre acceso al proceso}

El segundo escalón de las garantías que comprende el derecho a la tutela judicial efectiva, está integrado por el derecho de acceso al

${ }_{14}$ En el mismo sentido SSTC 206/2002, de 11 de noviembre, Fj. 2; 62/2002, de 11 de marzo, Fj. 2; 71/2001, de 26 de marzo, Fj. 3; 311/2000, de 18 de diciembre, Fj. 3; $35 / 1999$, de 22 de marzo.

15 STC 90/1985, de 22 de julio, Fj. 4..

16 Esta sentencia la comentamos en el siguiente apartado. 
proceso judicial legalmente previsto, para que a través de él el órgano judicial se pronuncie sobre la cuestión planteada.

El acceso al proceso implica que se reconozca el derecho a ser parte en él, y a promover la actividad jurisdiccional que desemboque en una decisión judicial sobre las pretensiones deducidas ${ }^{17}$, a toda persona que esté legitimada para ello. Este derecho al proceso de toda persona legitimada le permite abrir ante los Tribunales un proceso como actor o participar en él como demandado, con el fin de que «...en ningún caso puedan adoptar éstos una decisión que afecte a sus derechos e intereses sin haberles dado ocasión de ser oídos..." (ATC 232/1983, de 25 de mayo, Fj. único).

$\mathrm{El}$ art. 24.1 CE garantiza el derecho a acceder al proceso, respetándose los principios de bilateralidad, contradicción e igualdad de armas procesales ${ }^{18}$; como afirma el Tribunal Constitucional en su Sentencia $245 / 1988^{19}$, de 19 de diciembre, el art. 24.1 CE consagra «el derecho de audiencia bilateral configurado por el principio de contradicción».

En nuestro caso cuando las Cámaras legislativas deniegan el suplicatorio, decretando los órganos judiciales el sobreseimiento libre, podría decirse que el afectado sí tuvo acceso al proceso y que éste se sobreseyó; sin embargo, como vemos el Tribunal Constitucional considera que el acceso al proceso va más allá que la simple interposición de una acción judicial. Y afirma que la decisión de las Cámaras sobre el suplicatorio incide en la tutela judicial de los ciudadanos afectados por las conductas supuestamente delictivas de Diputados y Senadores, pues la disponibilidad del proceso penal se convierte en el objeto sobre el que deciden los órganos parlamentarios, de los que no puede afirmarse, en consecuencia, que sean ajenos a la prestación de la tutela judicial. «Esta, por el contrario, dependerá, en último término, de una actuación parlamentaria - la que conceda o deniegue el correspondiente suplicatorio-, actuación que adquiere relieve jurisdiccional, (...), no en cuanto suponga un enjuiciamiento en términos jurídicos de la conducta que motiva la solicitud del suplicatorio, lo que obviamente no lleva a cabo, sino en cuanto resuelve mediante un procedimiento específico sobre la pretensión de que ese enjuiciamiento se produzca en vía penal ${ }^{20}$.

17 SSTC 115/1984, de 3 de diciembre, Fj. 3; y 115/1988, de 10 de junio, Fj. 1.

18 SSTC 220/2002, de 25 de noviembre, Fj. 3; 216/2002, de 25 de noviembre, Fj. 2; 208/2002, de 11 de noviembre, Fj. 2; 199/2002, de 28 de octubre, Fj. 2;

19 FJ.3.

20 STC 90/1985, Fj. 4.. 
Lo mismo que ocurría con el derecho de acceso a la jurisdicción, la negativa de las Cámaras a conceder un suplicatorio deberá estar motivada y ser conforme a los fines que persigue la inmunidad parlamentaria, pues de lo contrario se vulnerará la tutela judicial efectiva concretada en el derecho de acceso al proceso.

\section{II.1.C. El derecho a no sufrir indefensión}

La idea de indefensión contiene, enunciándola de manera negativa, la definición del derecho a la defensa jurídica, lo que supone el empleo de los medios lícitos necesarios para preservar o restablecer una situación jurídica perturbada o violada consiguiendo una modificación jurídica que sea debida tras un debate (proceso), decidido por un órgano imparcial (jurisdicción) (STC 48/1984, de 4 de abril, Fj. 1). De forma que, entendida en sentido amplio, la indefensión engloba toda violación de los derechos encuadrables en el artículo 24 de la Constitución. Sin embargo, el propio Tribunal Constitucional ha perfilado un concepto más depurado de indefensión en el marco jurídico-constitucional.

Este concepto juridico-constitucional de indefensión no tiene porqué coincidir enteramente con la figura juridico-procesal de la indefensión. Es decir, la idea de indefensión no puede limitarse, restrictivamente, al ámbito de lo que pueda plantearse en un litigio concreto, sino que ha de extenderse a la interpretación desde el punto de vista constitucional de las Leyes reguladoras de los procesos. El concepto de indefensión constitucional implica una privación o limitación sustancial del derecho de defensa ${ }^{21}$ que comprende básicamente la posibilidad de acceder al proceso, efectuar alegaciones y probar lo alegado. Para que una situación de indefensión pueda considerarse constitucionalmente relevante, no basta con que se haya producido la vulneración de una norma fundamental, sino que es preciso que esa vulneración conlleve consecuencias prácticas que supongan la privación del derecho de defensa, así como perjuicios reales e indebidos para los intereses del afectado ${ }^{22}$.

Es decir, no se trata de una indefensión formal; «el derecho a la no indefensión - dice el TC - en su dimensión constitucional tiene ante todo un contenido material, de suerte que sólo resulta lesionado si las

21 SSTC 48/1984, Fj. 1; 155/1988, de 22 de julio, Fj. 4.

22 SSTC 48/1986, de 23 de abril Fj. 1, 68/1988, de 18 de abril, Fj. 3; ATC 966/1987, de 29 de julio, Fj. 2. 
partes no han podido de ningún modo proveer a la defensa de sus derechos e intereses legítimos en el proceso mediante las alegaciones oportunas" (ATC 1191/1987, de 26 de octubre, Fj. 3) 23. La indefensión constitucionalmente proscrita por el artículo 24.1 de la Constitución no es equiparable a una simple irregularidad procesal, sino a la imposibilidad real y efectiva de emplear los cauces procesales establecidos en defensa de los propios intereses y derechos (STC 220/2002, de 25 de noviembre, Fj. 3) ${ }^{24}$. Esta indefensión constitucionalmente relevante exige "una reducción a la nada de las posibilidades de defensa de quien la sufre con el consiguiente perjuicio de sus intereses» (STC 48/1986, Fj. 1) ${ }^{25}$.

La conclusión a la que se llega es doble: por una parte, no toda infracción de normas procesales se convierte por sí sola en indefensión con relevancia jurídico-constitucional y por ende en violación de lo ordenado por el artículo 24 de la Constitución; y, por otra parte, la calificación de la indefensión con relevancia jurídico-constitucional, o con repercusión en el orden constitucional, ha de llevarse a cabo con la introducción de factores diferentes del mero respeto o infracción de la norma procesal.

Como afirma el Profesor ALZAGA VILLAAMIL el artículo 24.1 de la Constitución «implica un mandato y una obligación para los poderes legislativo y judicial; la obligación de los poderes públicos de acatar la Constitución y el resto del ordenamiento jurídico implica un deber de lealtad de todos ellos en el ejercicio de sus propias competencias, y la sujeción de los poderes públicos al ordenamiento constitucional ha requerido, no solamente una importante labor legislativa en materia procesal para dar efectividad a la prohibición de indefensión, sino también, ha impuesto una interpretación de las normas procesales acorde con la Constitución, y especialmente con la interpretación que el TC ha dado al artículo $24 \mathrm{CE}^{26}$.

${ }^{23}$ Frente a esta distinción que la jurisprudencia del Tribunal Constitucional hace entre indefensión formal y material, DIEZ-PICAZO JIMÉNEZ entiende que la idea de indefensión es única: aquella que tiene incidencia en el fallo, debiendo limitarse el Tribunal Constitucional al juicio sobre la incidencia puesto que de otra forma ocuparía el lugar de los órganos judiciales («Artículo $24 \mathrm{CE}$. Garantías procesales», en Comentarios a la Constitución española de 1978 (dir. O. Alzaga Villaamil), T. III, Madrid, Edersa-Cortes Generales, 1996, págs. 55 y 56).

${ }^{24}$ En el mismo sentido SSTC 208/2002, de 11 de noviembre, Fj. 2; 86/1997, de 22 de abril, Fj. 1; 105/1995; 6/1992; 101/1990; 43/1989; ATC 660/1987, de 27 de mayo, Fj. 2. Y ATC 660/1987, de 27 de mayo, Fj. 2.

${ }^{25}$ En el mismo sentido STC 89/1986, y ATC 31/1987, de 14 enero, Fj. 1.

26 ALZAGA VILLAAMIL, Oscar: «La prohibición de indefensión. El derecho a la defensa", Boletín del Ilustre Colegio de Abogados de Madrid, n. ${ }^{\circ}$ 17, Marzo 2001, pág. 15 . 
En el contexto del art. 24 de la Constitución, la indefensión se caracteriza por suponer una privación o una limitación del derecho de defensa, que, si se produce por vía legislativa, sobrepasa el límite del contenido esencial prevenido en el art. 53 (STC 48/1984, Fj. 1)27. En el supuesto que venimos analizando cuando se decreta el sobreseimiento libre por la denegación del suplicatorio, este derecho se ve afectado totalmente.

Se podría decir que el sobreseimiento libre tiene su apoyo en el artículo 7 de la Ley de 9 de febrero de 1912. Sin embargo, como hemos visto, la indefensión constitucional se extiende a la interpretación de las Leyes reguladoras de los procesos. Es decir, nos encontramos ante una norma preconstitucional que afecta de forma negativa a un derecho fundamental, anulándolo completamente. En este sentido la jurisprudencia constitucional ha reiterado que los órganos judiciales están obligados a aplicar las normas procesales teniendo en cuenta el fin perseguido por el legislador, evitando que cualquier exceso formalista las convierta en obstáculos procesales impeditivos de la tutela judicial efectiva; y evitando, también, interpretaciones de las normas basadas en criterios desproporcionados entre los fines que la norma preserva y los intereses que se sacrifican ${ }^{28}$. Como afirma el Profesor ALZAGA VILLAAMIL cuando el artículo 24 de la Constitución «convierte a los órganos jurisdiccionales en tutores directos de los derechos fundamentales, les está imponiendo la obligación de tutelar, con carácter efectivo, las posibles situaciones antijurídicas en que puedan verse comprometidos los ciudadanos ${ }^{29}$.

En nuestro caso, el fin que persigue la Constitución de 1978 al establecer la inmunidad parlamentaria es que no se altere la independencia, la composición o el funcionamiento de las Cámaras legislativas. Alteración que no se produce si un proceso penal se reabre respecto a una persona que en su día perteneció a las Cámaras pero que ya no forma parte de ellas. Por eso, los Jueces y Tribunales deberían inaplicar el artículo 7 de la Ley de 9 de febrero de 1912, por

27 SSTC 70/1984, de 11 de junio; 155/1988, de 22 de julio, Fj. 4: «La indefensión con efectos jurídico-constitucionales y, en consecuencia, la lesión de los derechos fundamentales reconocidos en el art. 24 de la Constitución, se produce únicamente cuando el interesado, de modo injustificado, ve cerrada la posibilidad de impetrar la protección judicial de sus derechos o intereses legítimos».

28 SSTC 12/2003, de 28 de enero, Fj. 4; 108/2000, de 5 de mayo, Fj. 3; 157/1989, de 5 de octubre; $124 / 2002$, de 20 de mayo, Fj. 3; 206/2002, de 11 de noviembre, Fj. 2; 62/2002, de 11 de marzo, Fj. 2; 71/2001, de 26 de marzo, Fj. 3; 311/2000, de 18 de diciembre, Fj. 3; 35/1999, de 22 de marzo.

${ }^{29}$ ALZAGA VILLAAMIL, Oscar: «La prohibición de ...», op. cit. pág. 18. 
ser contrario totalmente al derecho a la tutela judicial efectiva concretada en el derecho a no sufrir indefensión.

\section{II.1.D. El derecho a obtener una resolución fundada en Derecho}

Conforme a la doctrina del Tribunal Constitucional, el derecho a la tutela judicial efectiva consagrado en el art. 24.1 CE comporta, como contenido esencial, el obtener de los órganos jurisdiccionales una resolución razonada y fundada en Derecho sobre el fondo de las pretensiones deducidas por las partes.

Sin embargo, la respuesta a la que las partes tienen derecho, no tiene que ser siempre sobre el fondo del asunto. Al tratarse de un derecho prestacional de configuración legal, su ejercicio y dispensación están supeditados a la concurrencia de los presupuestos y requisitos establecidos por el legislador para cada sector del ordenamiento procesal, por lo que el derecho a la tutela judicial efectiva se satisface igualmente cuando los órganos judiciales pronuncian una decisión de inadmisión o meramente procesal, apreciando razonadamente la concurrencia en el caso de un óbice fundado en un precepto expreso de la Ley.

Ahora bien, aunque son válidas las decisiones de inadmisión o las que no entran en el fondo del asunto, el principio general que debe mover a los órganos jurisdiccionales es el de solucionar definitivamente la cuestión planteada, de forma que los presupuestos y requisitos que las leyes exijan han de ser respetuosos con el contenido esencial del derecho fundamental ${ }^{30}, \mathrm{y}$ «valorados en su sentido y finalidad, es decir, mediante la razonable apreciación del medio en que consisten y del fin que con él se persigue, medidos en su justa proporción y ello para evitar la preponderancia de lo que es sólo instrumento (medio) entendido literalmente, con mengua de la finalidad última de la función judicial, no otra que la de resolver definitiva y eficazmente los conflictos que a ella se le someten. A ello se refiere el art. 24.1 cuando habla de «tutela efectiva»» (STC 11/1988, de 2 de febrero, Fj. 4) ${ }^{31}$.

30 SSTC 27/2003, de 10 de febrero, Fj. 4; 211/2002, de 11 de noviembre, Fj. 2; 172/2002, de 30 de septiembre, Fj. 3; 106/2002, de 6 de mayo, Fj. 4; 86/2002, de 22 de abril, Fj. 1; 61/2000, de 13 de marzo, Fj. 3; 36/1997, de 25 de febrero, Fj. 3; 164/1991, de 18 de julio, Fj. 1.

31 En el mismo sentido SSTC 69/1984, de 11 de junio, Fj. 2; 93/1984, de 16 de octubre, FJ. 5: «el contenido normal del derecho a la tutela judicial efectiva consiste en 
Además, como afirma el Profesor ALZAGA VILLAAMIL, «el artículo 9.3 de la Constitución establece un principio de carácter general que se dirige de manera directa a todos los poderes públicos, para que, en el desarrollo de sus funciones respectivas, observen escrupulosamente las previsiones legales a las que están sometidos y razonen sus resoluciones evitando incidir en la arbitrariedad ${ }^{32}$. Cuando este principio se traslada al ámbito de la función jurisdiccional se desdobla en dos prescripciones diferentes: por un lado en la necesidad de dar una respuesta a cualquier petición que le planteen las partes, y por otro, en que dicha respuesta esté suficientemente razonada (STS, Sala Segunda, de 23 de junio de 1997). Lo que significa que la sentencia deberá estar suficientemente motivada, y ser congruente con lo solicitado.

Es decir, el contenido normal del derecho a la tutela judicial efectiva es obtener una resolución sobre el fondo de la cuestión planteada, debiendo los Jueces y Tribunales interpretar toda la legislación en el sentido más favorable a esa posibilidad de entrar en el fondo del asunto y a la vez, aplicar restrictivamente aquellas normas que permitan no pronunciarse sobre el fondo ${ }^{33}$.

\section{CONCLUSIONES}

Con todo ello, podemos afirmar que el artículo 24.1 de la Constitución reconoce el derecho a la tutela judicial efectiva de los jueces y tribunales. Dicho derecho se desglosa, a su vez, en distintos derechos

obtener una resolución de fondo, si bien tal derecho se satisface cuando la resolución es de inadmisión si se dicta en aplicación razonada de una causa legal, razonamiento que ha de responder a una interpretación de las normas conforme a la Constitución y en el sentido más favorable para la efectividad del derecho fundamental».

32 ALZAGA VILLAAMIL, Oscar: «La prohibición de ...», op. cit. , pág. 29.

33 SSTC 160/2001, de 5 de julio, Fj. 3; 158/2000, de 12 de junio, Fj. 5; 63/1999, de 26 de abril, Fj. 2; 11/1988, de 2 de febrero, Fj. 4; 57/1988, de 5 de abril, Fj. 1; 200/1988, de 26 de octubre, Fj. 2; 211/2002, de 11 de noviembre, Fj. 2: La efectividad del derecho a la jurisdicción no consiente interpretaciones y aplicaciones de los requisitos legales caracterizados por el rigorismo, formalismo o la desproporción entre los fines que preservan y la consecuencia de cierre del proceso que conllevan, con eliminación u obstaculización injustificada del derecho a que un órgano judicial resuelva sobre el fondo de la pretensión a él sometida". Por ello, entiende el Alto Tribunal que la resolución del órgano judicial "puede incurrir en inconstitucionalidad que dé lugar a la estimación del recurso de amparo, como sucede en los casos en que [...] la normativa no se ha interpretado en el sentido más favorable para la efectividad del derecho fundamental y ello ha impedido entrar en el fondo" (SSTC 69/1984, de 11 de junio, Fj. 2; 211/2002, de 11 de noviembre, Fj. 2; 19/1983, Fj. 4). 
que pueden verse afectados por la decisión de las Cámaras legislativas acerca de la concesión o no de un suplicatorio.

Cuando las Cámaras legislativas deciden acerca de un suplicatorio, la disponibilidad del proceso penal se convierte en el objeto mismo de su decisión. Por ello cuando denieguen el suplicatorio deberán hacerlo de forma motivada y en razón de los fines que persigue la inmunidad parlamentaria, pues de lo contrario se vulnerará la tutela judicial efectiva.

Por otra parte, el hecho de que las Cámaras denieguen el suplicatorio conlleva que el Juez o Tribunal decrete el sobreseimiento libre del parlamentario afectado por el proceso penal, lo que impide que una vez que el parlamentario pierde tal condición se pueda acudir a la vía jurisdiccional para que el afectado en su día por la conducta presuntamente delictiva del ex-parlamentario, pueda obtener una resolución judicial que entre en el fondo del asunto, viendo satisfechas, en su caso sus pretensiones.

Sin embargo, los órganos judiciales están obligados a aplicar las normas que contienen requisitos procesales, teniendo en cuenta el fin perseguido por el legislador al establecerlos, evitando cualquier exceso formalista que los convierta en obstáculos procesales de la tutela judicial efectiva, y que supongan una clara desproporción entre los fines que la causa preserva y los intereses que se sacrifican. Por ello, la aplicación del artículo 7 de la ley de 9 de febrero de 1912 que supone el sobreseimiento libre, y por tanto produce el efecto de cosa juzgada, es contraria a la tutela judicial efectiva concretada en los de derechos de acceso a la jurisdicción, de acceso al proceso, a no sufrir indefensión y a obtener una resolución fundada en Derecho. 